\title{
Management of Fractures of Metacarpals and Phalanges of Hand with Mini External Fixator
}

\section{Shivaraj B ${ }^{1}$, Shiva Kumar Bingi², Parvez Ahmad Ganie ${ }^{3}$, Aquib Suheil Pasha $^{4}$ and Madhan Jeyaraman ${ }^{3 *}$}

${ }^{1}$ Department of Orthopaedics, Fortis Hospital, Bengaluru, Karnataka, India

${ }^{2}$ Department of Orthopaedics, Relief Hospital, Warangal, Telangana, India

${ }^{3}$ Department of Orthopaedics, School of Medical Sciences and Research, Sharda

University, Greater Noida, Uttar Pradesh, India

${ }^{4}$ Department of Orthopaedics, JJM Medical College, Davangere, Karnataka, India

*Corresponding Author: Madhan Jeyaraman, Department of Orthopaedics, School of Medical Sciences and Research, Sharda University, Greater Noida, Uttar Pradesh, India.
Received: July 27, 2021

Published: August 12, 2021

(C) All rights are reserved by Madhan

Jeyaraman., et al.

\section{Abstract}

Introduction: Metacarpal and phalangeal fractures are more common injuries in hand, either closed or open. These injuries are encountered every day. Most of the fractures are treated conservatively, but for unstable fractures, open fractures, comminuted fractures operative treatment is indicated. This study was undertaken to evaluate the functional outcome of closed or open metacarpal and phalangeal fractures treated with a mini-external fixator.

Materials and Methods: From July 2016 to June 2019, a total of 40 cases of metacarpal and phalangeal fractures of the hand were treated with a mini-external fixator. All patients were screened using inclusion and exclusion criteria. Follow up was done till 12 months to evaluate the fracture union and range of movements by DASH score.

Results: The mean soft tissue healing was 2.56 weeks. The mean fracture healing was 14.45 weeks. The results were found excellent in $55 \%$, good in $22.5 \%$ cases, fair in $15 \%$ cases, whereas poor results were seen in $7.5 \%$ of fractures.

Conclusion: External fixation is an adequate alternative treatment for unstable phalangeal and metacarpal fractures which are open or accompanied by severe soft-tissue injuries.

Keywords: Mini-External Fixator; Metacarpal; Phalanx; DASH Score

\section{Introduction}

The hand is the most vulnerable part of the body prone to injuries especially in road traffic accidents, fall, blunt trauma, industrial, agricultural and sports injuries resulting in fractures of phalanges and metacarpal which may be open or closed fractures. Fractures of metacarpals and phalanges are the most common among upper limb bony injuries and contribute to about $10 \%$ of total fractures among them [1-3]. Fractures of the metacarpal and phalanges are more common in males and the peak incidence is at the age of 10 - 40 years [4,5]. Fractures of the proximal phalanx (PP) are more frequently encountered than the middle or distal phalanx [6]. The displacement with considerable deformity is typical when the proximal phalanx is fractured. 
Fractures of the hand are common problems in hand surgery. Bone fragments are comparatively small and comminuted hence reduction is hard to be conducted. A few of the factors which affect the treatment include injury to the tendons, ligaments and articular capsule. The principle in treating this type of fracture include anatomical reduction, stable fixation and early mobilisation $[7,8]$.

Fractures of the hand can be managed by non-operative and operative management. Non-operative treatments like splinting, buddy strapping and slab application [9]. Operatively by k-wire, plates and screws etc leads to further damage to the soft tissues, stiffness of the joints, delay in rehabilitation [10].

External fixation for fractures of the hand allows fracture reduction and maintain normal bony length and provides rigid external support [11]. External fixation allows mobilisation of joints proximal and distal to the fracture. External apparatus is used as an alternative to internal fixation. Advantages like it simplify surgery being both quick and easy to apply, maintains alignment, avoids internal dissection, minimal soft tissue damage allowing early mobilisation [12].

We aimed to assess the functional outcome of closed and open fractures of metacarpals and phalanges using a mini-external fixator.

\section{Materials and Methods}

After obtaining institute ethical clearance, a prospective study was carried out from July 2016 to June 2019 with a total of 40 patients with metacarpal and phalangeal fractures.

Patients 18-65 years of age, patients with unstable fractures of the hand, intraarticular and extra-articular fractures, open fractures, and multiple fractures were included in the study. Patients with severely crushed hand injuries with extensive soft tissue damage, pathological fractures, associated vascular and tendon injuries, and delayed presentation for management were excluded from the study.

All the patients were treated by mini external fixator as shown in figure 1 to 4 and followed up at the immediate post-op period and at the end of 1,2 , and 6 months and evaluated for functional outcome using DASH score as shown in figure 5 to 8 .

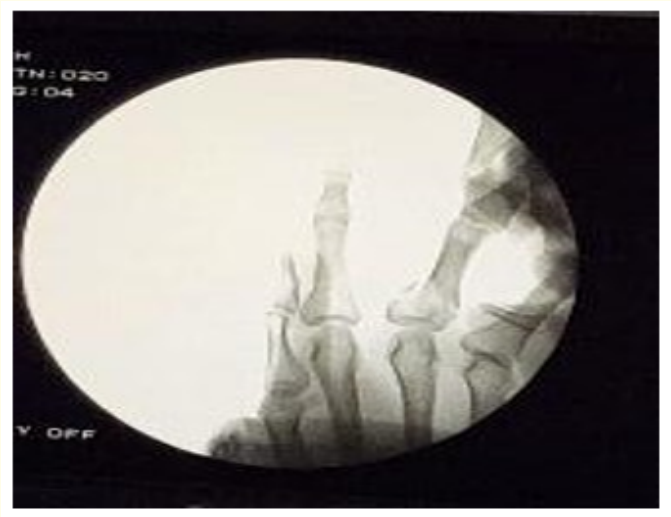

Figure 1: Reduction checked under C-ARM.

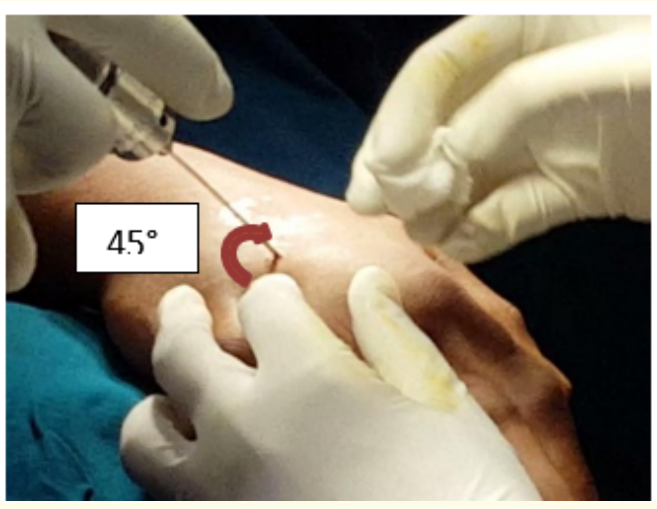

Figure 2: K-wire drilled at an angle of 45 degrees.

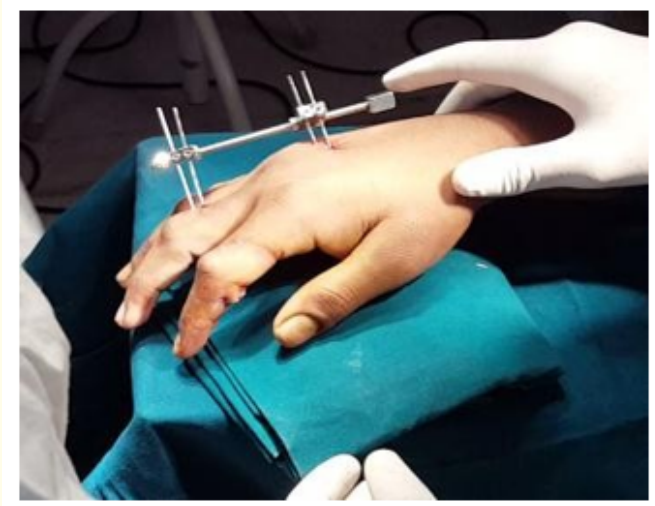

Figure 3: Distractor frame connected to k-wires. 


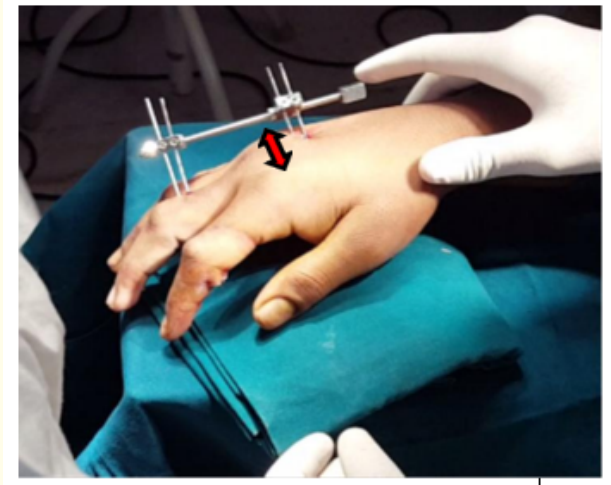

Figure 4: Space of 5-7 mm left between connecting systems and skin.

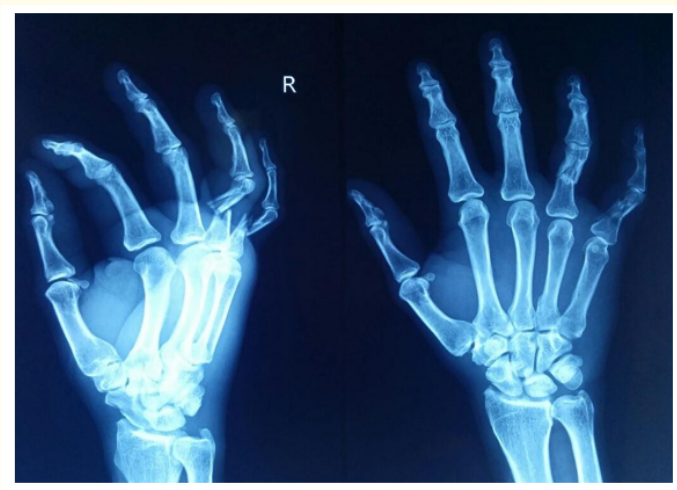

Figure 5: Radiograph of fracture of shaft of $4^{\text {th }}$ and $5^{\text {th }}$ proximal phalanx of the right hand.

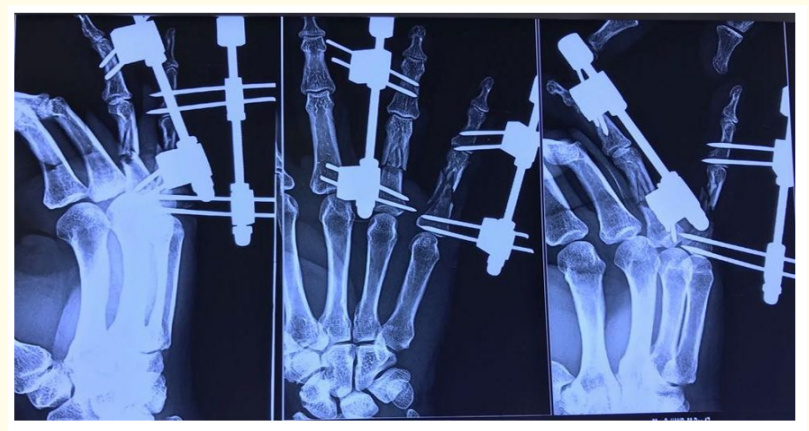

Figure 6: Post-op X-ray showing proximal phalanx fracture fixed with the mini-external fixator.

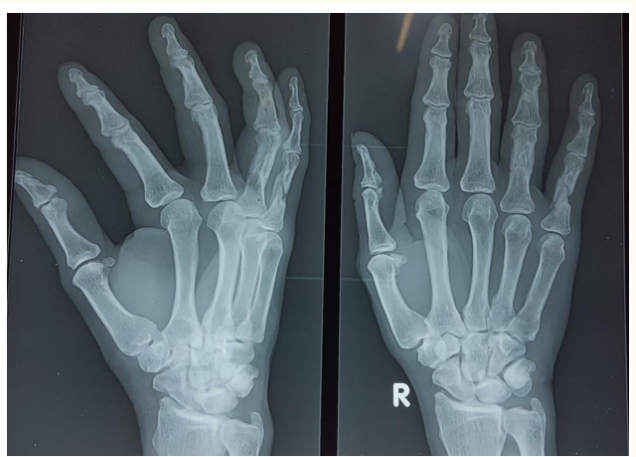

Figure 7: Union of $4^{\text {th }}$ and $5^{\text {th }}$ proximal phalangeal fractures of the right hand at 8 weeks.

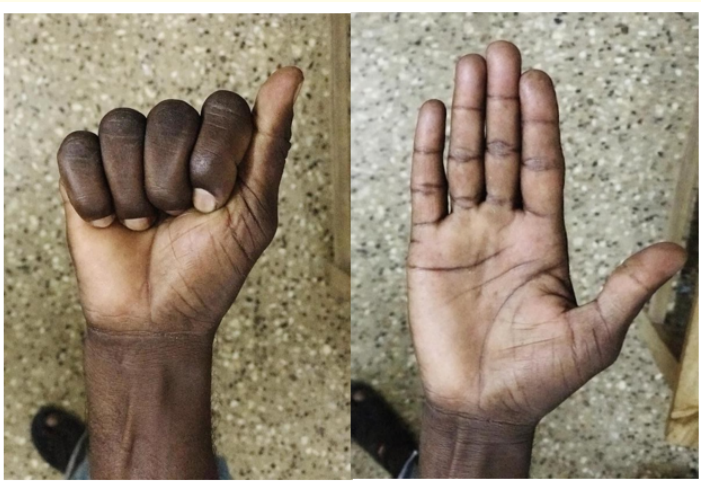

Figure 8: Range of movements.

The descriptive statistics were reported as mean (SD) for continuous variables, frequencies (percentage) for categorical variables. Data were statistically evaluated with IBM SPSS Statistics for Windows, Version 25.0, IBM Corp, Chicago, IL. The functional outcome was measured by a repeated-measures ANOVA test with a Greenhouse-Geisser correction. The p-value of less than 0.05 was considered significant.

\section{Results}

The most common age group presenting was $<30$ years $(45 \%)$. The mean age of the study participants were $33.85 \pm 10.15$. Males $(65 \%)$ outnumbered females $(35 \%)$ in our series. A total of $72.5 \%$ 
of the patients had RTA and $27.5 \%$ had an occupational mode of injury and assault.

Out of 40 cases, 9 cases (according to Swanson., et al. classification, 6 cases were type 1 and 3 cases were type 2) reported with open fractures. Three cases were reported with the distal end of radius fracture in 2 cases and shaft of radius fracture in 1 case. The fractures united for 8 cases (20.0\%) in 8 - 12 weeks, 26 cases $(65.0 \%)$ in 13 - 16 weeks and 6 cases $(15 \%)$ in 17 - 20 weeks. The duration of JESS in situ for 16 cases (40.0\%) in 3 - 4 weeks, 18 cases $(45.0 \%)$ in 5 - 6 weeks and 6 cases $(15 \%)$ in 7 - 8 weeks. The time taken for different parameters related to surgical outcome were tabulated in table 1.

\begin{tabular}{|l|c|c|}
\hline Variable & Mean & SD \\
\hline Surgery Time (in days) & 2.50 & 4.40 \\
\hline Healing time soft tissue (in weeks) & 2.56 & 0.88 \\
\hline Healing time fracture (in weeks) & 14.45 & 2.68 \\
\hline Ex-fix in situ (in weeks) & 5.15 & 1.13 \\
\hline
\end{tabular}

Table 1: Time taken for different parameters.

The results were found excellent in 55\%, good in $22.5 \%$ cases, fair in $15 \%$ cases, whereas poor results were seen in $7.5 \%$ of fractures. A total of 14 cases (35\%) have partial stiffness, 8 cases (20\%) had malunion, 3 cases $(7.5 \%)$ had pinloosening, and 2 cases (5\%) had pin tract infection. A repeated-measures ANOVA with a Greenhouse-Geisser correction determined that the mean DASH score differed statistically significantly between time points $[\mathrm{F}(1.726,32.78)=159.804, \mathrm{p}<0.001]$ as shown in table 2 .

\begin{tabular}{|l|c|c|c|c|c|}
\hline Timeline & Mean & SD & $\begin{array}{c}\text { (95\% CI) } \\
\text { Lower } \\
\text { bound }\end{array}$ & $\begin{array}{c}\text { (95\% CI) } \\
\text { Upper } \\
\text { bound }\end{array}$ & P-value \\
\hline $1^{\text {st }}$ month & 86.400 & 3.011 & 80.098 & 92.702 & $<0.001$ \\
\hline $3^{\text {rd }}$ month & 64.250 & 2.971 & 58.032 & 70.468 & $<0.001$ \\
\hline $6^{\text {th }}$ month & 52.300 & 3.096 & 45.820 & 58.780 & $<0.001$ \\
\hline
\end{tabular}

Table 2: DASH score.

\section{Discussion}

Fractures of metacarpals and phalanges are probably the most common fractures in the skeletal system and are often neglected as minor injuries $[10,13]$. Most of the fractures are treated conservatively, but fixation is often indicated in unstable fractures, intra-articular fractures, open fractures and multiple fractures. Mini-external fixator acts by the principle of ligamentotaxis to achieve closed reduction without requiring immobilization of the adjacent joint [14].

Various studies by Jenkin., et al. [15] [external fixation apparatus], Parson., et al. [16] [Shearer micro-external fixator], Mullett., et al. [17] ["S" Quattro dynamic external fixator], Kontakis., et al. [18] [mini-Hoffman external fixation], Fricker., et al. [19] [AO mini-external fixator], Inanami., et al. [20] small dynamic external finger fixator], Johnson., et al. [21] [dynamic external spring fixator], Li., et al. [22] [mini external fixator + limited internal fixation], El-Shaer., et al. [23] [mini external fixator], and Yaseen., et al. [24] [mini external fixator] reported excellent to good functional outcome in metacarapal and phalangeal fractures of hand with the follow-up duration of 3 to 9 months.

Gupta., et al. reported at the end of 3 months follow up, an excellent total active range of motion was observed with plate and screw/screw fixation technique (100\%) and closed reduction and percutaneous Kirschner wire fixation (60\%) for metacarpal and phalangeal fractures of the hand with finger stiffness as the most common reported complication in this series [25]. Out of 30 patients with 37 fractures of metacarpal and phalanges, Bakki., et al. reported excellent in $35.13 \%$, good in $40.55 \%$ cases, in $18.92 \%$ whereas poor results in $5.40 \%$ with JESS fixation [5]. With UMEX (universal mini external fixator), Gupta., et al. managed 45 patients with metacarpal and phalanges fracture of the hand. The results were found excellent in 35.55 , good in 37.77 , fair in 13.33 , whereas poor results were seen in $13.33 \%$ of fractures [14].

Kapur., et al. reported a study on intra-articular fractures of the proximal interphalangeal (PIP) joint treated with dynamic external fixation. All fracture cases are united with good joint congruency. All patients achieved a good range of motion of the PIP joint but with some restriction of full flexion (mean, 20 degrees). No complications were reported during the follow-up [26]. Drenth., et al. used an external fixator for phalangeal and metacarpal fractures and reported that the functional outcome was excellent in middle phalangeal fractures than proximal phalangeal fractures [27].

Shehadi., et al. employed external fixation with methylmethacetylate rods in 26 hand fracture cases (19 metacarpal 
and 11 phalangeal) and reported the percentage return of total range of motion in phalangeal fractures varied from $66 \%$ to $98 \%$ (mean $84 \%$ ), and in metacarpal fractures, it varied from $77 \%$ to 100\% (mean 96\%) [12]. Various parameters have been studies among published literature were tabulated in table 3 .

\begin{tabular}{|c|c|c|c|c|}
\hline \multicolumn{2}{|l|}{ Parameters } & $\begin{array}{l}\text { Bakki., } \\
\text { et al. [5] }\end{array}$ & $\begin{array}{l}\text { Gupta., } \\
\text { et al. [14] }\end{array}$ & Our study \\
\hline \multicolumn{2}{|l|}{ No. of patients } & 30 & 45 & 40 \\
\hline \multirow{4}{*}{$\begin{array}{l}\text { Fractures } \\
\text { distribution }\end{array}$} & $\begin{array}{l}\text { Proximal } \\
\text { phalanx }\end{array}$ & 21 & 15 & 17 \\
\hline & $\begin{array}{l}\text { Middle } \\
\text { phalanx }\end{array}$ & 04 & 14 & 13 \\
\hline & Distal phalanx & - & - & 02 \\
\hline & Metacarpal & 13 & 16 & 08 \\
\hline \multicolumn{2}{|l|}{ Fixator used } & UMEX & UMEX & $\begin{array}{c}\text { JESS } \\
\text { distractor }\end{array}$ \\
\hline \multicolumn{2}{|l|}{ Fixator in situ } & 4.42 weeks & $\begin{array}{c}5.21 \\
\text { weeks }\end{array}$ & 5.15 weeks \\
\hline \multicolumn{2}{|c|}{ Mean soft tissue healing } & 2.61 weeks & $\begin{array}{c}2.32 \\
\text { weeks }\end{array}$ & 2.56 weeks \\
\hline \multicolumn{2}{|c|}{ Mean fracture healing } & 12.77 weeks & 12 weeks & $\begin{array}{c}14.45 \\
\text { weeks }\end{array}$ \\
\hline \multirow{6}{*}{ Complications } & $\begin{array}{l}\text { Pin tract } \\
\text { infection }\end{array}$ & 5 & 12 & 03 \\
\hline & Pin loosening & 3 & 12 & 02 \\
\hline & Joint stiffness & 10 & 15 & 14 \\
\hline & Malunion & 2 & 06 & 08 \\
\hline & Non union & 0 & 0 & 0 \\
\hline & Osteomyelitis & 0 & 0 & 0 \\
\hline \multirow[t]{2}{*}{ Results } & $\begin{array}{l}\text { Excellent/ } \\
\text { Good }\end{array}$ & 28 & 33 & $22 / 9$ \\
\hline & Fair/poor & 09 & 12 & $6 / 3$ \\
\hline
\end{tabular}

Table 3: Comparison of various surgical parameters in the published literature.

In our series of 40 cases, the results were found excellent in 22 (55\%) cases, good in $9(22.5 \%)$ cases, fair in $6(15 \%)$ cases, whereas poor results were seen in $3(7.5 \%)$ cases. A repeated-measures ANOVA with a Greenhouse-Geisser correction determined that the mean DASH score differed statistically significantly between time points $[\mathrm{F}(1.726,32.78)=159.804, \mathrm{p}<0.001]$.

\section{Conclusion}

External fixation is an adequate alternative treatment for unstable phalangeal and metacarpal fractures which are open or accompanied by severe soft-tissue injuries. It is a minimally invasive procedure, reduces surgical trauma to soft tissue and protects vascular integrity. Understanding the biomechanical principles and correct applicationmethodology is essential.

\section{Conflicts of Interest}

Nil.

\section{Funding Sources}

Nil.

\section{Bibliography}

1. Moore A and Varacallo M. "Metacarpal Hand Fracture”. In: StatPearls. Stat Pearls Publishing (2021).

2. Kamath JB., et al. "Current concepts in managing fractures of metacarpal and phalanges". Indian Journal of Plastic Surgery 44.2 (2011): 203-211.

3. Dean BJF and Little C. "Fractures of the metacarpals and phalanges". Orthopaedics and Trauma 25.1 (2011): 43-56.

4. AlMugren TS., et al. "Epidemiology and patterns of the hand and distal forearm fractures at King Abdul-Aziz Medical City, Riyadh, KSA". Journal of Taibah University Medical Sciences 11.1 (2016): 86-90.

5. Bakki SS., et al. "Stabilisation of metacarpal and phalangeal fractures with JESS fixation". Journal of Evidence Based Medicine and Health Care 4.12 (2017): 661-668.

6. Singh J., et al. "Outcome of closed proximal phalangeal fractures of the hand". The Indian Journal of Orthopaedics 45.5 (2011): 432-438.

7. Zyluk A and Budzyński T. "Treatment of metacarpal and phalangeal fractures-a review". Chirurgia Narządów Ruchu i Ortopedia Polska 71.4 (2006): 299-308.

8. Wahl EP and Richard MJ. "Management of Metacarpal and Phalangeal Fractures in the Athlete". Clinic in Sports Medicine 39.2 (2020): 401-422. 
9. Giddins GEB. "The non-operative management of hand fractures". The Journal of Hand Surgery European 40.1 (2015): 3341.

10. Kollitz KM., et al. "Metacarpal fractures: treatment and complications". Hand 9.1 (2014): 16-23.

11. Margić K. "External fixation of closed metacarpal and phalangeal fractures of digits. A prospective study of one hundred consecutive patients". The Journal of Hand Surgery: British 310.1 (2006): 30-40.

12. Shehadi SI. "External fixation of metacarpal and phalangeal fractures". Journal of Hand Surgery 16.3 (1991): 544-550.

13. McDaniel DJ and Rehman UH. "Phalanx Fractures of the Hand". In: StatPearls. StatPearls Publishing (2021).

14. Gupta SV., et al. "Management of fractures of metacarpals and phalanges of hand with UMEX (universal mini external fixator)". International Journal of Orthopaedics Sciences 28.4 (2015): 965-970.

15. Jenkin E. "Treatment of intra-articular metacarpal and phalangeal fractures with an external fixation minidevice". Handchirurgie, Mikrochirurgie, Plastische Chirurgie 15.3 (1983): 198-203.

16. Parsons SW., et al. "External fixation of unstable metacarpal and phalangeal fractures". The Journal of Hand Surgery: British 17.2 (1992): 151-155.

17. Mullett JH., et al. "Use of the "S" Quattro dynamic external fixator in the treatment of difficult hand fractures". The Journal of Hand Surgery: British 24.3 (1999): 350-354.

18. Kontakis GM., et al. "Rolando's fracture treated by closed reduction and external fixation". Archives of Orthopaedic and Trauma Surgery 117.1-2 (1998): 84-85.

19. Fricker R., et al. "[AO external mini-fixateur for the hand bones. Surgical technique and initial experiences]". Chirurg 67.7 (1996): 760-763.

20. Inanami H., et al. "Dynamic external finger fixator for fracture dislocation of the proximal interphalangeal joint". Journal of Hand Surgery American 18.1 (1993): 160-164.
21. Johnson D., et al. "Dynamic external fixation for complex intraarticular phalangeal fractures". The Journal of Hand Surgery: British 29.1 (2004): 76-81.

22. Li W., et al. "Management of intra-articular fracture of the fingers via mini external fixator combined with limited internal fixation". Chinese Medical Journal 122.21 (2009): 2616-2619.

23. El-Shaer. "Results of management of recent fractures of phalanges of the hand by a mini external fixator". Menoufi a Medical Journal 28.4 (2015): 965-970.

24. Yaseen G., et al. "Results of mini external fixator in metacarpal and phalangeal fractures". Pakistan Armed Forces Medical Journal 66.5 (2016): 715-719.

25. Gupta R., et al. "Evaluation of surgical stabilization of metacarpal and phalangeal fractures of hand". The Indian Journal of Orthopaedics 41.3 (2007): 224-229.

26. Kapur B., et al. "An Alternative Technique for External Fixation of Traumatic Intra-articular Fractures of Proximal and Middle Phalanx". Techniques in Hand and Upper Extremity Surgery 19.4 (2015): 163-167.

27. Drenth DJ and Klasen HJ. "External fixation for phalangeal and metacarpal fractures". The Journal of Bone and Joint Surgery British 80.2 (1998): 227-230.

\section{Volume 4 Issue 9 September 2021} (C) All rights are reserved by Madhan Jeyaraman., et al. 